\title{
Editorial
}

\section{Gastro-oesophageal reflux is not a major cause of brief resolved unexplained events in infants}

Cite as: Jilani NZ, Hussain A, Al Ansari K, et al. Gastrooesophageal reflux is not a major cause of brief resolved unexplained events in infants. Breathe 2019; 15: e32-e39.

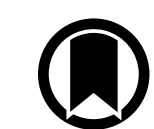

CrossMark

\section{Introduction}

The clinical scenario of an infant presenting to the emergency department with the parents reporting a history of the child stopping breathing, choking or "turning blue" at home is a well-recognised event and accounts for between 2.5 and 4.1 hospital admissions per 1000 live births [1, 2]. The infant is often back to their normal self with a normal clinical examination. This event used to be called an apparent life-threatening event (ALTE) [1] and recently it has been suggested that it should now be called a brief resolved unexplained event (BRUE) [2]. Gastro-oesophageal reflux (GOR) has long been considered to be a common reason for an ALTE and some studies have listed it as an underlying cause in up to $54 \%$ of patients [3-6]. Does the evidence support this belief?

\section{ALTEs and BRUEs}

The term ALTE was proposed in 1986 [1] and, prior to this, such events were classified as "near-miss sudden infant death syndrome (SIDS)" [6]. It became clear that babies with near-miss events were not at increased risk of SIDS, and this terminology was replaced with the term $\operatorname{ALTE}[1,6]$. It was considered that this new term was both vague and subjective. Symptoms appearing frightening to caregivers, such as periodic breathing, could be manifestations of normal neonatal physiology [7]. In 2016, the American Academy of Pediatrics (AAP) released a clinical guideline for practitioners recommending that the term ALTE be replaced by BRUE [2]. The aim was to allay the anxiety to the caregivers brought about by the use of the term ALTE, as well as to give practitioners clear management guidance by stratifying such infants into high- and low-risk groups.

It should be clear that a BRUE is diagnosed only when there is no other explanation for a qualifying event, following an appropriate history and thorough physical examination. The AAP guidelines give clear guidance for the management of low-risk infants and these infants can be managed safely at home. A recent meta-analysis of the risk of death in infants who have experienced a BRUE supports the returnhome management approach. The risk of death is about the same as the baseline risk of death during the first year of life. For patients evaluated in an emergency department and deemed as low risk, there is no need for them to be investigated and admitted to hospital [8]. The AAP guideline does not provide recommendations for investigation of those that are stratified in the high-risk group.

\section{GOR and gastro-oesophageal reflux disease}

National Institute for Health and Care Excellence (NICE) guidelines published in 2015 are very clear about the definitions of GOR and gastro-oesophageal reflux disease (GORD). GOR is "The passage of gastric contents into the oesophagus. It is a common

@ERSpublications

Although it is often stated that gastro-oesophageal reflux is the most common cause of a brief resolved unexplained event or apparent life-threatening event, there are very few data to support the hypothesis of cause and effect http://bit.ly/2FjknUy 
physiological event that can happen at all ages from infancy to old age and is often asymptomatic. It is more common after feeds or meals. In many infants it is associated with a tendency to "overt regurgitation" - the visible regurgitation of feeds" [9]. GORD is "Gastro-oesophageal reflux that causes symptoms (for example, discomfort or pain) severe enough to merit medical treatment or that has associated complications (such as oesophagitis or pulmonary aspiration)" [9].

GOR is very common in infants for several reasons, including the physiological low tone of the lower oesophageal sphincter in infancy, liquid feeds and supine position, and occurs in about $40 \%$ of infants. Onset is usually before 8 weeks of age and may be frequent, with $5 \%$ of those affected having six or more episodes a day. It does not usually need further investigation or treatment [9]. NICE, in 2015, commented that GOR causes episodes of apnoea or ALTEs only rarely, but physicians should consider referral for specialist investigations if reflux is suspected as a possible factor [9]. The Pediatric Gastroesophageal Reflux Clinical Practice Guidelines from 2018 list BRUEs as one of the 23 signs and symptoms of GORD but do not make a comment about the likely prevalence of this presenting symptom [10]. One of the biggest difficulties about examining the effect of GOR on BRUEs is that there is a huge variation in definitions, investigative tools, outcome measures and prevalence reports used in the literature on GOR [11, 12]. For example, pH studies, regarded by many as the standard diagnostic tool for GOR, only measures acid reflux $(\mathrm{pH}<4)$. It is difficult to interpret studies in infants with a presumed association between apnoea and GOR based on $\mathrm{pH}$ studies because the buffering effect of feeding may result in predominantly non-acid GOR. Patients potentially at risk cannot be reliably identified by $\mathrm{pH}$ studies. Exclusive use of $\mathrm{pH}$ is therefore not suitable for the detection of all GOR-associated apnoeas in infants. The $\mathrm{pH}$-independent multichannel intraluminal impedance (MII) technique is a more sensitive diagnostic tool for this approach [13].

\section{Methods}

A search of the literature was performed using the following PECO (population, exposure, control, outcome) question: "In previously well infants (population), are those with GOR (exposure) compared to infants with no GOR (control) more likely to present with a BRUE (outcome)?"

To find primary sources, Medline was searched via PubMed and Embase was searched separately, using the following terms: "GE Reflux" OR "Gastroesophageal Reflux" AND "BRUE" OR "Brief Resolved Unexplained Event" OR "ALTE” OR "Apparent life-threatening episode" OR "Apnoea”. The Cochrane library was searched in January 2019 with the terms "GE Reflux” AND “BRUE” OR “ALTE” OR “Apnoea”.

\section{Results}

The search strategy resulted in 153 citations, and after removing some duplicates and non-Englishlanguage studies, abstracts of 117 papers were reviewed. The hospital librarian (Abdul Sulaiman, Sidra Medical Library, Doha, Qatar) assisted with the literature search and retrieval of some original articles. The majority of articles were review articles or retrospective case note reviews of cases admitted with the diagnosis of ALTE to see what causative aetiology was considered. No relevant reviews were identified. A total of 12 articles were deemed relevant to our clinical question. All articles were separately reviewed by N.Z. Jilani and A. Hussain, and included one systematic review (including eight studies) [3], two retrospective note reviews $[14,15]$ and nine prospective investigative studies [13, 16-23] (table 1).

\section{Discussion}

There continues to be much debate about the underlying aetiology of BRUEs and whether GOR is causative [6, 24]. MEYER et al. [25] retrospectively reviewed infants admitted with the diagnosis of ALTE. Re-applying the BRUE definition to this group, they found only $23 \%$ of subjects falling within the definition of BRUE and only one of the 87 patients in their review fitted the low-risk BRUE criteria. This illustrates the difficulty in the interpretation of the literature.

In a systematic review from 2004, in eight studies including 642 infants presenting with ALTE, the most common clinical diagnosis, at 35\%, was GOR [3]. Puntis and Booth [26] questioned these findings, as six of the eight studies did not have $\mathrm{pH}$ impedance studies and in the absence of confirmation of low oesophageal $\mathrm{pH}$, they wondered whether those children may have had physiological GOR rather than GORD. It was concluded that demonstration of a significant temporal relationship between lower oesophageal $\mathrm{pH}$ and apnoea was crucial in establishing a causative relationship [27].

\section{Evidence for GOR as a cause of ALTE/BRUE}

In 1989, SeE et al. [23] compared 16 infants with ALTE and six control infants who solely had clinical $\mathrm{GOR}$, and used prolonged $\mathrm{pH}$ studies in conjunction with pulse oximetry and transthoracic impedance pneumocardiography. Despite the absence of vomiting in 14 out of 16 patients with ALTE, the incidence of GOR was similar in ALTE compared to the control group (95\% versus $100 \%$ ). There was a significant drop in arterial oxygen saturation $(<90 \%$ for $>3 \mathrm{~min}$ ) noted in 14 out of 16 patients with ALTE compared with no desaturation in the control group. It was observed that 54 out of the 60 desaturation episodes commenced within $3.9 \pm 0.4 \mathrm{~min}$ 


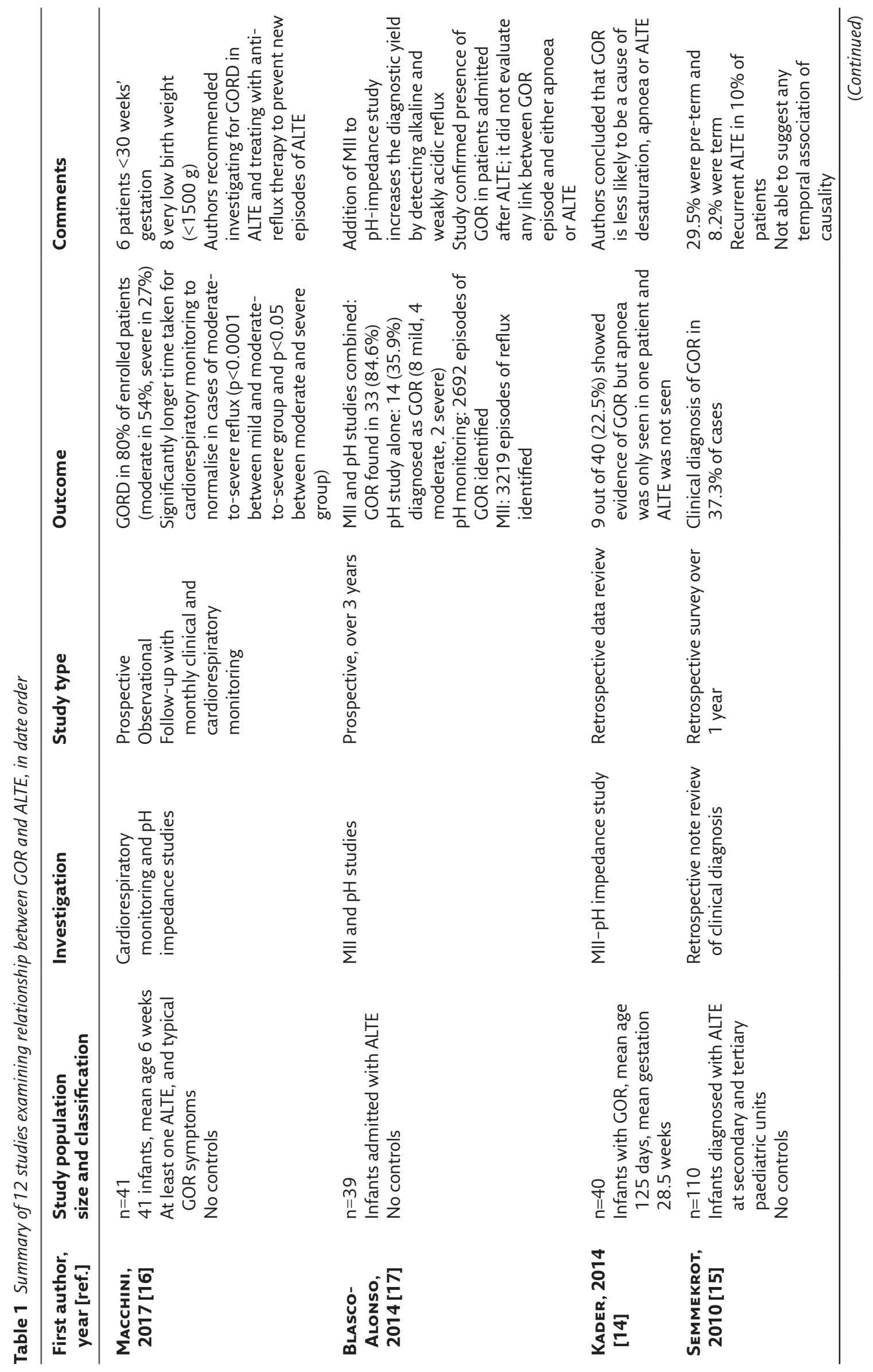




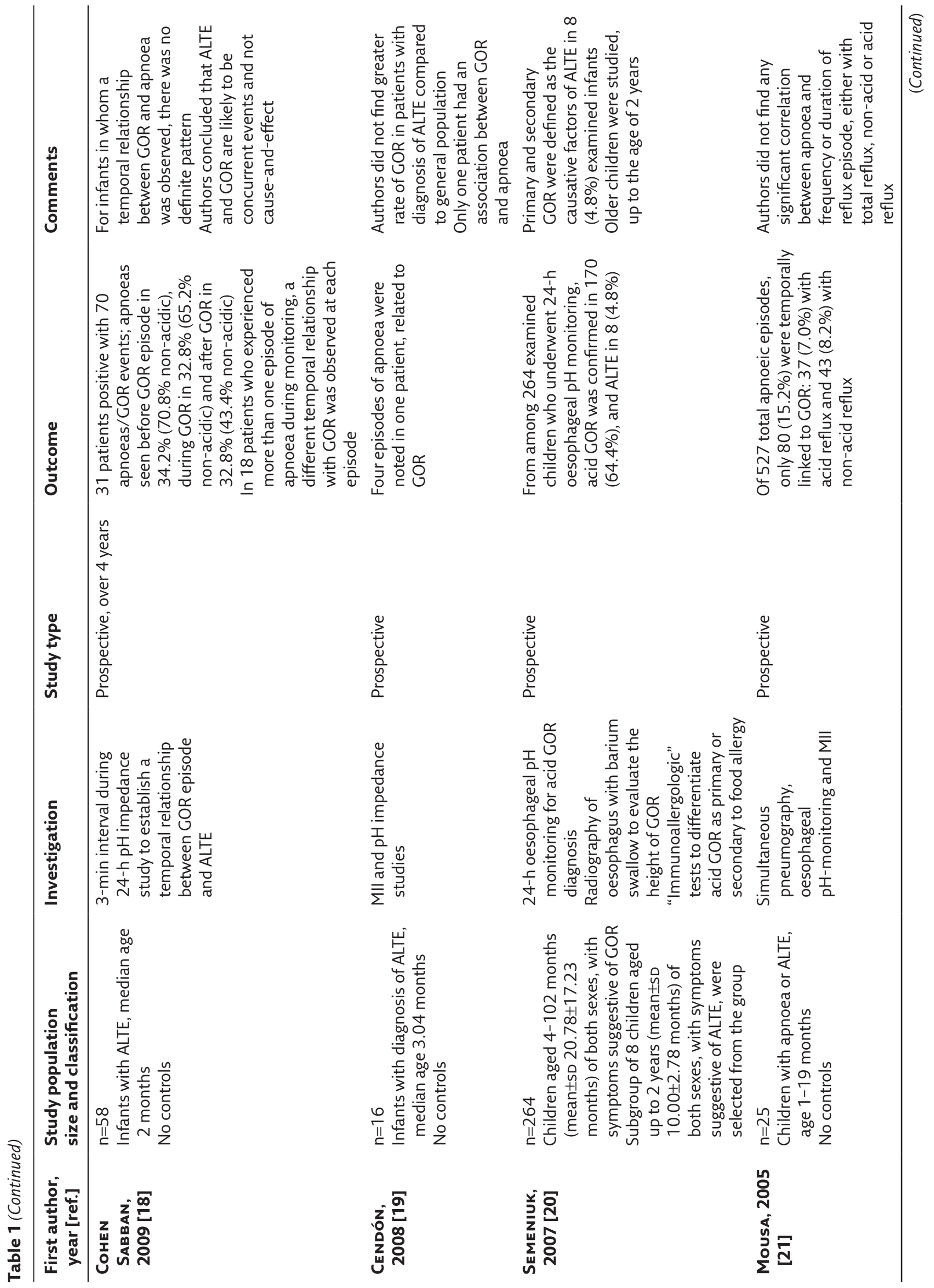




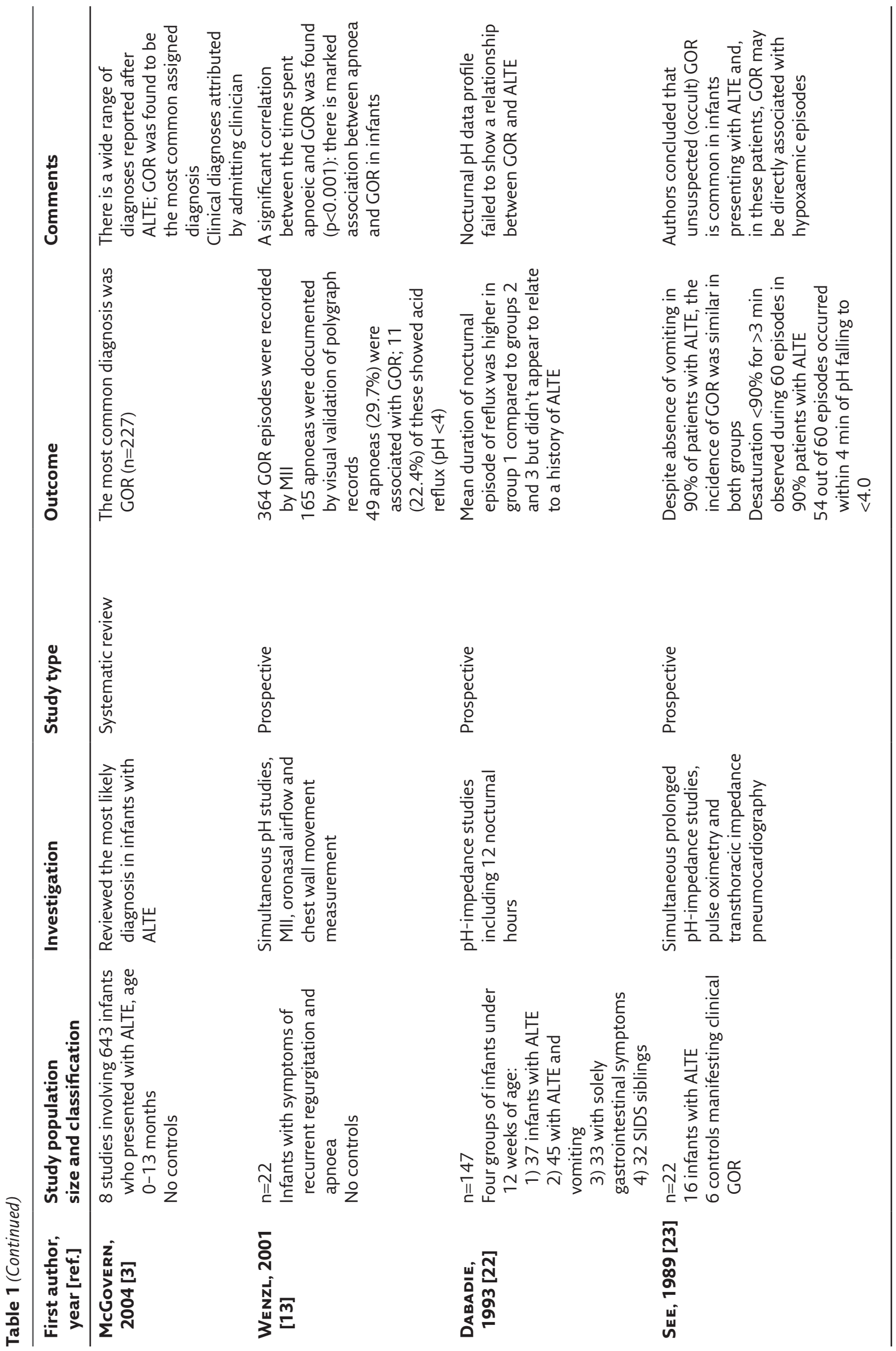


(mean \pm SD) of onset of drop in oesophageal $\mathrm{pH}$ to $<4$. They concluded that GOR is common in infants presenting with ALTE and, in these patients, GOR may be directly associated with reflex hypoxaemic events [23]. GOR was similar in both groups; the desaturation was more common in the ALTE group. This may represent a different physiological process rather than being related directly to the GOR.

WENZL et al. [13] found significant correlation between the time spent apnoeic and GOR in 22 infants. The aim of this study was to investigate the temporal association of apnoea and GOR with the $\mathrm{pH}$-independent $\mathrm{MII}$ technique. Infants with recurrent regurgitation or respiratory symptoms suggestive of apnoea were investigated simultaneously with $\mathrm{MII}, \mathrm{pH}$ monitoring and polysomnography. MII patterns, $\mathrm{pH}$ study, oronasal air flow and chest wall movement were recorded and analysed. In 22 infants, 364 GOR episodes were recorded by MII. 165 apnoeas were documented by visual validation of polygraph records. 49 apnoeas (29.7\%) were associated with GOR; 11 (22.4\%) of these showed acid reflux $(\mathrm{pH}<4)$. A significant correlation between the time spent apnoeic and GOR was found $(p<0.001)$. Their conclusion was that there is marked association between apnoea and GOR in infants.

\section{Evidence against GOR as a cause of ALTE/BRUE}

In 1993, DABADIE et al. [22] looked for a relationship between GOR and apnoea in 147 infants aged $\leq 12$ weeks. A 24-h pH impedance study was performed in four groups: 1) 37 infants who presented an ALTE; 2) 45 infants with an ALTE and chronic digestive symptoms (recurrent vomiting); 3) 33 infants with digestive symptoms only; and 4) 32 SIDS siblings. The percentage duration of oesophageal $\mathrm{pH}<4$ was measured during $24 \mathrm{~h}$ and 12 nocturnal hours (20:00-08:00 h). In addition, the mean duration of nocturnal episodes of reflux (MDNR) was calculated (duration of $\mathrm{pH}$ $<4$ per 12 nocturnal hours divided by the number of reflux episodes). No significant difference was found in the four groups for percentage duration of oesophageal $\mathrm{pH}<4$. Nocturnal reflux was present in all groups (40\% in group 1, 55\% in group 2, 49\% in group 3 and $63 \%$ in group 4 ). The MDNR was higher in group 1 (12.3 $\pm 7.8 \mathrm{~min})$ versus group 2 $(6.8 \pm 5.1 \mathrm{~min})$ and group $3(6.7 \pm 3.2 \mathrm{~min})(\mathrm{p}<0.05)$. High MDNR did not appear to be related to a history of ALTE, since the MDNR in group 2 was identical to group 3. The nocturnal $\mathrm{pH}$ impedance profile failed to show a relationship between GOR and ALTE.

Mousa et al. [21] did not find significant correlation between apnoea (using an apnoea definition of $10 \mathrm{~s}$ ) and frequency or duration of reflux episode, either with total reflux, non-acid or acid reflux using $\mathrm{pH}$ impedance. In 25 infants with an ALTE history and 527 total apnoeic episodes, only 80 apnoeic episodes (15.2\%) were temporally linked to GOR: 37 (7.0\%) with acid reflux and 43 (8.2\%) with non-acid reflux.

In 2008, Cendón et al. [19] examined 16 infants with a diagnosis of ALTE who underwent $\mathrm{pH}$ impedance studies and found no correlation between ALTE and GOR. Another larger prospective study by Cohen SABBan et al. [18] focused on the 3-min interval on $24 \mathrm{~h} \mathrm{pH} / \mathrm{MIl}$ monitoring when an episode of GOR happened within 3 min of an apnoea, to see if the apnoea occurred before, during or after an episode of GOR. Out of 58 infants evaluated, 31 were positive, with 70 apnoea/GOR events recorded. The percentage of apnoeas seen before a reflux episode was $34.2 \%$ (70.8\% nonacidic), during GOR was $32.8 \%$ (65.2\% non-acidic) and after GOR was 32.8\% (43.4\% non-acidic). In 18 patients who experienced more than one episode of apnoea during the recording, a different temporal relationship was observed between apnoea and GOR each time. The authors concluded that GOR and ALTE are just concurrent events without any temporal relationship between the two [18]. Similar findings were reported by KADER et al. [14] when they retrospectively reviewed case notes and data of $\mathrm{pH}$ impedance studies in infants with clinical GOR. They found that nine (22.5\%) out of 40 patients had evidence of GOR but apnoea and ALTE was present in only one patient in the study cohort, and concluded that an association between GOR and apnoea/ALTE is less likely.

In 2014, Blasco-Alonso et al. [17] confirmed that the addition of MII to traditional 24-h $\mathrm{pH}$ monitoring increases the diagnostic yield of GOR in patients with ALTE. It was inconclusive regarding the association with ALTE as the study did not investigate whether this high occurrence of GOR was a mere coincidence or there indeed was any association of causality. This was a prospective study of MII-pH monitoring performed on 39 infants $<12$ months of age admitted for ALTE over a 3-year period. There were $2692 \mathrm{pH}$ monitoring episodes, with a median (interquartile range $(\mathrm{IQR}))$ of $24(15-44)$ episodes patient $^{-1}, 1.30$ $(0.80-2.60)$ refluxes $\cdot \mathrm{h}^{-1}, 1(0-4)$ reflux episode $>5$ min per patient and clearance of 1.20 (0.702.20) $\mathrm{min} \cdot$ reflux $^{-1}$. With $\mathrm{pH}$ monitoring analysis, 14 children (35.9\%) could have been diagnosed with GOR based on the classical criteria. MII identified a total of 8895 events; only 3219 among them were refluxes, with a median (IQR) of 75 (54-111) refluxes patient ${ }^{-1}$ at a rate of 1.30 (1.3-2.6) episodes $\cdot \mathrm{h}^{-1}$. With the MII-pH monitoring combination there were mean \pm sD $21.60 \pm 15.21$ acid reflux episodes, 67.33 \pm 32.09 weakly acid and $3.34 \pm 7.23$ non-acid, giving a final total of 33 patients diagnosed with GOR.

A more recent study published in 2017 by MACCHINI et al. [16] looked at 41 infants with at least one ALTE and typical GOR symptoms who underwent $\mathrm{pH}$ studies and monthly cardiorespiratory monitoring. They found initial 
presence of GOR in $80 \%$ of patients $(54 \%$ moderate, $27 \%$ severe). The authors reported that it took longer for cardiorespiratory monitoring to normalise in cases of moderate-to-severe reflux. Based on these findings they recommended investigating for GOR in all cases of ALTE and starting anti-reflux therapy to prevent recurrence of ALTE-like episodes. It is worth noting that the study population included six premature babies of $<30$ weeks' gestation and the number of very low birth weight babies ( $<1500 \mathrm{~g})$ was eight. There was no direct aetiological connection established between apnoea/ALTE and GOR. SEMENIUk et al. [20] examined older children (aged 4-102 months) and found an association between ALTE and GOR in only $4.8 \%$ patients. SEMMEKROT et al. [15] found that clinical diagnosis of GOR was made in $37.3 \%$ of cases presenting with an ALTE but they were not able suggest any temporal association of causality.

\section{Conclusion}

These cross-sectional observational studies show that, although GOR is listed as the most common cause of ALTE, there are no strong data to support the hypothesis that GOR causes a BRUE or ALTE. There are data to show that symptoms (and MII and $\mathrm{pH}$ study evidence) of GOR are common in infants, and some children who have had BRUE or ALTE also have GOR. There are no clear data to suggest a temporal association of cause and effect.

One study reported that it took longer for cardiorespiratory monitoring to normalise in cases of moderate-to-severe reflux [16]. They included premature and very low birth weight babies but found no temporal association. There are other studies examining apnoea of prematurity and GOR, with the same overall conclusion that there is no temporal relationship between the two conditions [28, 29]. Wenzl et al. [13] did find a significant association but that may have been due to study design and their definition of apnoea being of a shorter duration ( $5 \mathrm{~s}$, compared to the standard definition of $15 \mathrm{~s}$ ), and this was an underpowered study of 22 patients.

Therefore, we conclude that the answer to the question of whether GOR is a major cause of BRUEs or ALTEs is "No".

\section{Affiliations}

\section{Nadeem Z. Jilani' ${ }^{1}$, Amna Hussain ${ }^{1}$, Khalid Al Ansari' ${ }^{1,2}$, Colin V.E. Powell ${ }^{1,3}$}

${ }^{1}$ Paediatric Emergency Dept, Sidra Medicine, Doha, Qatar. ${ }^{2}$ Clinical Paediatrics, Weill Cornell University Medical College, Education City, Qatar. ${ }^{3}$ Child Health School of Medicine, Cardiff University, Cardiff, UK.

\section{Conflict of interest}

None declared.

\section{References}

1. National Institutes of Health Consensus Development Conference on infantile apnea and home monitoring, Sept 29 to Oct 1, 1986. Pediatrics 1987; 79: 292-299.

2. Tieder JS, Bonkowsky JL, Etzel RA, et al. Brief resolved unexplained events (formerly apparent life-threatening events) and evaluation of lower-risk infants. Pediatrics 2016; 137 e20160590

3. McGovern MC, Smith MB. Causes of apparent life threatening events in infants: a systematic review. Arch Dis Child 2004 89: 1043-1048

4. Doshi A, Bernard-Stover L, Kuelbs C, et al. Apparent lifethreatening event admissions and gastroesophageal reflux disease: the value of hospitalization. Pediatr Emerg Care 2012 28: 17-21

5. Fu LY, Moon RY. Apparent life-threatening events: an update. Pediatr Rev 2012; 33: 361-368.

6. McFarlin A. What to do when babies turn blue: beyond the basic brief resolved unexplained event. Emerg Med Clin North Am 2018; 36: 335-347.

7. Kelly DH, Stellwagen LM, Kaitz E, et al. Apnea and periodic breathing in normal full-term infants during the first twelve months. Pediatr Pulmonol 1985; 1: 215-219.

8. Brand DA, Fazzari MJ. Risk of death in infants who have experienced a brief resolved unexplained event: a metaanalysis. J Pediatr 2018; 197: 63-67.
9. Davies I, Burman-Roy S, Murphy MS, et al. Gastro-oesophageal reflux disease in children: NICE guidance. BMJ 2015; 350: g7703.

10. Rosen R, Vandenplas $Y$, Singendonk $M$, et al. Pediatric Gastroesophageal Reflux Clinical Practice Guidelines: Joint Recommendations of the North American Society for Pediatric Gastroenterology, Hepatology, and Nutrition and the European Society for Pediatric Gastroenterology, Hepatology, and Nutrition. J Pediatr Gastroenterol Nutr 2018; 66: 516-554.

11. Singendonk M, Goudswaard E, Langendam M, et al. Prevalence of gastroesophageal reflux disease symptoms in infants and children: a systematic review. J Pediatr Gastroenterol Nutr 2019; 68: 811-817.

12. Singendonk MMJ, Brink AJ, Steutel NF, et al. Variations in definitions and outcome measures in gastroesophageal reflux disease: a systematic review. Pediatrics 2017; 140: e20164166.

13. Wenzl TG, Schenke S, Peschgens T, et al. Association of apnea and nonacid gastroesophageal reflux in infants: investigations with the intraluminal impedance technique. Pediatr Pulmonol 2001; 31: 144-149.

14. Kader A, Ong C, Logarajah V, et al. Multichanne intraluminal impedance-pH test correlation with cardio respiratory events in children. Neurogastroenterol Motil 2014; 26: Suppl. 1, 79-80. 
15. Semmekrot BA, van Sleuwen BE, Engelberts AC, et al. Surveillance study of apparent life-threatening events (ALTE) in the Netherlands. EurJ Pediatr 2010; 169: 229-236.

16. Macchini F, Morandi A, Cognizzoli P, et al. Acid gastroesophageal reflux disease and apparent life-threatening events: simultaneous $\mathrm{pH}$-metry and cardiorespiratory monitoring. Pediatr Neonatol 2017; 58: 43-47.

17. Blasco-Alonso J, Yun-Castilla C, Girón FernándezCrehuet $\mathrm{F}$, et al. Esophageal multichannel intraluminal impedance and $\mathrm{pH}$ testing in the study of apparent life threatening episode incidents in infants. Rev Esp Enferm Dig 2014; 106: 159-164.

18. Cohen Sabban J, Orsi M, Cuevas VF, et al. No particular sequence of events is observed in infants with ALTE and gastroesophageal reflux as measured by impedance. J Pediatr Gastroenterol Nutr 2009; 49: Suppl. 1, E84.

19. Cendón RG, Jiménez MJ, Valdés JA, et al. Importancia de la impedanciometría esofágica en el diagnóstico de los episodios aparentemente letales [Intraluminal impedance technique in the diagnosis of apparent life-threatening events (ALTE)]. Cir Pediatr 2008; 21: 11-14.

20. Semeniuk J, Kaczmarski M, Wasilewska J, et al. Is acid gastroesophageal reflux in children with ALTE etiopathogenetic factor of life threatening symptoms? Adv Med Sci 2007; 52: 213-221.

21. Mousa H, Woodley FW, Metheney M, et al. Testing the association between gastroesophageal reflux and apnea in infants. J Pediatr Gastroenterol Nutr 2005; 41 : 169-177.

22. Dabadie A, Blanchot I, Goter E, et al. Étude comparative des résultats de la $\mathrm{pH}$-métrie en fonction de son indication chez le nourrisson [Comparative study of results of $\mathrm{pH}$-metry in function of its indication in infants]. Pediatrie 1993; 48: 189-193.

23. See CC, Newman LJ, Berezin S, et al. Gastroesophageal reflux-induced hypoxemia in infants with apparent lifethreatening event(s). Am J Dis Child 1989; 143: 951-954.

24. Arane K, Claudius I, Goldman RD. Brief resolved unexplained event: new diagnosis in infants. Can Fam Physician 2017; 63: 39-41.

25. Meyer JS, Stensland EG, Murzycki J, et al. Retrospective application of BRUE criteria to patients presenting with ALTE. Hosp Pediatr 2018; 8: 740-745.

26. Puntis JW, Booth IW. ALTE and gastro-oesophageal reflux. Arch Dis Child 2005; 90: 653.

27. Puntis JW. "Apparent life threatening events" in sleeping infants: is gastroesophageal reflux ever to blame? J Clin Forensic Med 2003; 10: 97-101.

28. Peter CS, Sprodowski N, Bohnhorst B, et al. Gastroesophageal reflux and apnea of prematurity: no temporal relationship. Pediatrics 2002; 109: 8-11.

29. Di Fiore JM, Arko M, Whitehouse M, et al. Apnea is not prolonged by acid gastroesophageal reflux in preterm infants. Pediatrics 2005; 116: 1059-1063. 